\title{
Evaluasi E-Learning Menggunakan Pendekatan Technology Acceptance Model
}

\author{
Rio Jumardi ${ }^{1}$ \\ ${ }^{1}$ Program Studi Teknik Informatika Sekolah Tinggi Teknologi Bontang \\ Jl. Letjen S. Parman, No.48, Kel. Belimbing, Kec. Bontang Barat, Kota Bontang, Kalimantan Timur \\ email : riojumardi@stitek.ac.id
}

\begin{abstract}
The use of information technology using the internet has been widely used in various fields including in the field of higher education in order to improve the quality of education. One of the utilization of technology that has been done in STITEK Bontang is implementation of information system in learning process using E-Learning. E-Learning has been implemented in 2019 and used as a means of supporting lectures that are applied online that can be utilized by lecturers and students to make the learning process where and at any time. Evaluation of E-Learning needs to be done to know the user's response to the newly implemented system. User feedback will be used to early anticipate to improve ELearning performance in supporting learning process at STITEK Bontang. The research approach done on research is quantitative research. Research conducted by analyzing the results of the questionnaire of 110 students who have used $E$ Learning. The quantitative approach done in this study is to explain the relationship between variables using the adoption model of the Technology Acceptance Model (TAM). Data analysis using Partial Least Square method with SMART Software PLS 2.0 M3. The results proved that, Perceived Usefulness and Perceived Ease of Use significantly affects of Attitude Towards Using, Perception of ease of use affects significantly of Perceived Usefulness, Perceived Usefulness and Attitude Towards Using significantly affects of behavioral intention and behavioral Intention significantly affects of Actual System Usage. In general, users can receive and use E-Learning in the implementation of learning but needs improvement in the quality of the system, especially when students will collect the lecturer assignment.
\end{abstract}

Keywords - E-Learning, PLS, Evaluation of System Information, TAM

Abstrak - Penggunaan teknologi informasi menggunakan internet telah banyak digunakan diberbagai bidang termasuk didalamnya pada bidang pendidikan tinggi dalam rangka peningkatan kualitas pendidikan. Salah satu pemanfaatan teknologi informasi yang dilakukan di lingkungan STITEK Bontang adalah implementasi penggunaan sistem informasi berbasis internet dalam proses pembelajaran menggunakan aplikasi E-Learning. E-Learning telah diimplementasikan pada tahun 2019 dan digunakan sebagai sarana pendukung perkuliahan yang diterapkan secara online yang dapat dimanfaatkan oleh dosen dan mahasiswa untuk melakukan proses pembelajaran dimana dan kapan saja. Evaluasi terhadap E-Learning perlu dilakukan untuk mengetahui tanggapan pengguna terhadap sistem yang baru diimplementasikan. Tanggapan pengguna akan dijadikan langkah antisipasi dini agar dilakukan perbaikan dan peningkatan performa E-Learning dalam mendukung proses pembelajaran di STITEK Bontang.Pendekatan penelitian yang dilakukan pada penelitian a dalah penelitian kuantitatif. Pendekatan kuantitatif yang dilakukan dalam penelitian ini adalah dengan cara menjelaskan hubungan antar variabel menggunakan model adopsi dari Technology Acceptance Model (TAM). Penelitian dilakukan dengan menganalisis hasil kuisioner dari 110 mahasiswa yang pernah menggunakan E-Learning. Analisis data menggunakan metode Partial Least Square dengan Software SMART PLS 2.0 M3. Hasil penelitian membuktikan bahwa, Persepsi Kegunaan dan Persepsi Kemudahan Penggunaan berpengaruh secara signifikan terhadap Sikap Terhadap Perilaku, Persepsi Kemudahan Penggunaan berpengaruh secara signifikan terhadap Persepsi Kegunaan, Persepsi Kegunaan dan Sikap Terhadap Perilaku berpengaruh secara signifikan terhadap Niat Perilaku serta Niat Perilaku berpengaruh secara signifikan terhadap Penggunaan Nyata Sistem. Secara umum, pengguna dapat menerima dan menggunakan E-Learning dalam pelaksanaan pembelajaran namun perlu adanya peningkatan kualitas sistem khususnya pada saat mengumpulkan tugas perkuliahan.

Kata Kunci- E-Learning, PLS, Evaluasi Sistem Informasi, TAM

\section{PENDAhUluan}

Penggunaan teknologi informasi khususnya pemanfaatan internet di Indonesia menunjukkan tren positif dari tahun ke tahun. Hal ini ditunjukkan oleh hasil survei yang dilakukan oleh Asosiasi Penyelenggara Jasa Internet Indonesia (APJII) bahwa penetrasi pengguna internet di Indonesia mencapai $64,8 \%$ dari total penduduk keseleruhan ${ }^{1}$. Penggunaan teknologi informasi menggunakan internet telah banyak digunakan diberbagai bidang termasuk didalamnya pada bidang pendidikan tinggi. Pemanfaatan teknologi informasi di dunia pendidikan khususnya pendidikan tinggi dilakukan dalam rangka peningkatan kualitas pendidikan agar mencapai tujuan institusi yang efektif dan efisien ${ }^{2}$.

Sekolah Tinggi Teknologi (STITEK) Bontang merupakan salah satu institusi pendidikan tinggi yang menggunakan teknologi informasi dalam menjalankan organisasinya. Salah satu pemanfaatan teknologi informasi di STITEK Bontang adalah penggunaan sistem informasi berbasis internet 
dalam proses pembelajaran. Sistem informasi yang digunakan dalam proses belajar mengajar di STITEK Bontang adalah aplikasi E-Learning. Elearning digunakan oleh dosen untuk memberikan materi maupun tugas perkuliahan. Sedangkan untuk mahasiswa, E-Learning digunakan untuk mengakses materi perkuliahan, pengumpulan tugas dan kuis serta keperluan perkuliahan lainnya. Dosen dan mahasiswa juga dapat berkomunikasi secara langsung dan interaktif melalui forum diskusi yang terdapat pada E-Learning. Penggunaan aplikasi pembejaran berbasis online bukan ditujukan untuk mengganti perkuliahan secara tatap muka ${ }^{3}$. ELearning digunakan sebagai sarana pendukung perkuliahan yang diterapkan secara online yang dapat dimanfaatkan oleh dosen dan mahasiswa untuk melakukan proses pembelajaran dimana dan kapan saja.

Evaluasi terhadap sistem informasi adalah langkah yang digunakan agar pengguna yakin akan sistem informasi yang telah diterapkan pada sebuah institusi. Evaluasi dilakukan juga dalam rangka peningkatan penggunaan sistem informasi yang telah diimplementasikan. Dalam kajian ilmu sistem informasi dan kajian interaksi manusia dan keomputer terdiri dari evaluasi pra implemntasi dan pasca implemntasi. Evaluasi yang dilakukan pra implementasi bertujuan untuk menganalisa tingkat penerimaan sistem informasi yang akan diterapkan. Semakin tinggi tingkat penerimaan teknologi maka semakin tinggi pula tingkat pemanfaatan teknologi dimasa yang akan datang ${ }^{4}$. Sedangkan evaluasi pasca implementasi akan fokus kepada kepuasan pengguna dan manfaat yang diperoleh dengan adanya sistem informasi.

Salah satu metode atau pendekatan yang digunakan untuk mengevaluasi tingkat penerimaan teknologi adalah Technology Acceptance Model. Technology Acceptance Model (TAM) merupakan suatu model hasil pengembangan dari Theory of Reasoned Action (TRA) oleh Davis ${ }^{5}$. yang mempelajari perilaku penerimaan seorang individu dalam menerima suatu sistem informasi. Perkembangan TAM telah berevolusi diantaranya perubahan dari UTAUT, TAM 2 dan TAM 3. Masing-masing model tersebut mempunyai kontribusi penting dan unik sebagai dasar evaluasi penerimaan pengguna Teknologi Informasi ${ }^{6}$.

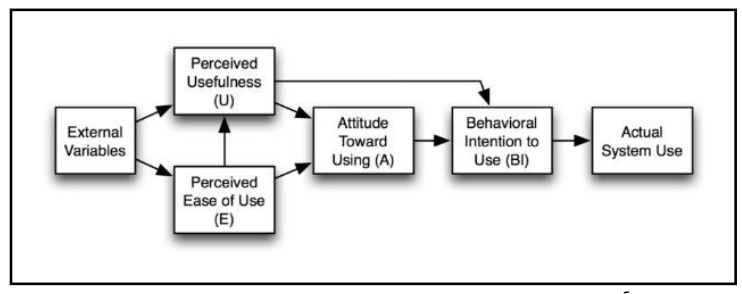

Gbr. 1 Technology Acceptance Model (TAM) ${ }^{5}$

Persepsi kegunaan (perceived usefulness) menggambarkan tingkat kepercayaan seseorang bahwa penggunaan sistem menggunakan teknologi informasi dengan keyakinan bahwa prestasi dan kinerja akan meningkat. Penggunaan suatu teknologi dipercaya akan mendatangkan manfaat bagi pemakainya menjadi ukuran dalam konsep ini.

Kemudahan penggunaan yang dirasakan (perceived ease of use) menggambarkan tingkat kepercayaan seseorang bahwa penggunaan sistem informasi merupakan hal yang mudah dan akan mengurangi tenaga, pikiran dan waktu yang digunakan untuk mempelajari dan menggunakan sistem informasi. Pekerjaan akan lebih mudah jika menggunakan sistem informasi dibandingkan menggunakan cara manual.

Sikap terhadap penggunaan (attitude towards use) merupakan kecenderungan tanggapan awal atas kondisi yang menyenangkan maupun tidak menyenangkan pada suatu objek tertentu. Secara teoritis, sikap merupakan refleksi perasaan seseorang atas objek dalam kondisi baik atau buruk, menguntungkan atau merugikan yang muncul karena seseorang memiliki nilai yang ditentukan oleh kepercayaan atas objek tersebut. Kepercayaan baru seseorang sehingga membawa perubahan pada sikap dapat dipengaruhi oleh perilaku tertentu pada kondisi yang berbeda.

Perilaku (behavior) dilakukan karena individu mempunyai niat atau keinginan untuk melakukan atau niat berperilaku akan menentukan perilakunya yang dipengaruhi oleh motivasi tertentu. Niat berperilaku (behavioral intention) adalah suatu keinginan seseorang untuk melakukan suatu perilaku tertentu atau kecenderungan seseorang untuk tetap menggunakan teknologi tertentu yang dapat diprediksi dari sikap perhatiannya terhadap teknologi tersebut.

Perilaku adalah penggunaan sesungguhnya (actual usage) teknologi itu sendiri atau kondisi nyata penggunaan sistem informasi. Perilaku pada adasarnya sulit diobservasi dan diukur melalui daftar pertanyaan, namun penggunaan sistem informasi dapat diprediksi dengan baik dengan menggunakan variabel niat berperilaku (behavioral intention) menggunakan Technology Acceptance Model ${ }^{7}$.

Layanan akademik E-Learning STITEK Bontang dapat diakses pada halaman website dengan alamat http://e-learning.stitek.ac.id. ELearning pada STITEK Bontang diimplementasikan pada tahun 2019. Evaluasi terhadap E-Learning dilakukan untuk mengetahui tanggapan pengguna terhadap sistem yang baru diimplementasikan. Umpan balik dari pengguna akan dijadikan langkah antisipasi dini agar dilakukan perbaikan dan peningkatan performa E-Learning dalam mendukung proses pembelajaran di STITEK Bontang. Evaluasi juga dilakukan untuk mengetahui keberhasilan penerapan sistem informasi di lingkungan STITEK Bontang. 


\section{METODOLOGI PENELITIAN}

Agar penelitian dapat berjalan secara sistematis dan tidak menyimpang dari tujuan penelitian, maka perlu adanya suatu alur penelitian sehingga dapat berjalan secara runtut dan sistematik. Pada tahap ini penelitian dimulai dengan pengumpulan data dengan melakukan studi literatur dari buku, jurnal dan artikel yang berhubungan dengan Model penelitian dan E-Learning. Selanjutnya bahan yang telah terkumpul digunakan untuk menyelesaikan masalah. Tahap selanjutnya adalah ditarik perumusan masalah yang menjadi fokus dalam penelitian ini dan merujuk pada tema dan obyek penelitian yang dipilih, sehingga penelitian ini dapat dilakukan.

Pada tahap pemecahan masalah peneliti mendeskripsikan permasalahan dengan mengacu pada masalah-masalah yang dapat diteliti serta mencari dan mengumpulkan informasi data mengenai gejala-gejala dan fenomena yang berkaitan dengan masalah implementasi ELearning. Sebelum data diolah dan dianalisis, terlebih dahulu dilakukan pengujian terhadap kualitas data untuk mengetahui validitas dan realiabilitas dari jawaban yang diberikan responden. Ada ketentuan yang berlaku pada sebuah kuesioner, yaitu keharusan untuk valid dan reliabel. Kuisioner penelitian berisi demografi responden dan pertanyaan sesuai variabel yang diukur dengan skala likert $^{10,11,12}$.

Pendekatan penelitian yang dilakukan pada penelitian adalah penelitian kuantitatif. Pendekatan kuantitif yang dilakukan dalam penelitian ini adalah dengan cara menjelaskan hubungan antar variabel dalam Technology Acceptance Model disertai dengan pengujian hipotesis. Adapun hipotesis pada penelitian ini adalah

H1: Persepsi Kemudahan Penggunaan (Perceived Ease of Use $(P E U))$ berpengaruh positif terhadap Persepsi Kegunaan (Perceived Usefulness $(P U))$.

H2: Persepsi Kegunaan (Perceived Usefulness $(P U))$ berpengaruh positif terhadap Sikap terhadap Perilaku (Attitude Towards Using $(A T U))$.

H3: Persepsi Kemudahan Penggunaan (Perceived Ease of Use (PEU)) berpengaruh terhadap Sikap terhadap Perilaku (Attitude Towards Using $(A T U))$.

H4: Sikap terhadap Perilaku (Attitude Towards Using (ATU)) berpengaruh positif terhadap Niat Perilaku (Behavioral Intention (BI)).

H5: Persepsi Kegunaan (Perceived Usefulness $(P U))$ berpengaruh positif terhadap Niat Perilaku (Behavioral Intention (BI)).

H6: Niat Perilaku (Behavioral Intention (BI)) berpengaruh terhadap Penggunaan Nyata Sistem (Actual System Usage (ATU)).

Konstruk hipotesis pada penelitian ini dapat dilihat pada Gambar 2.

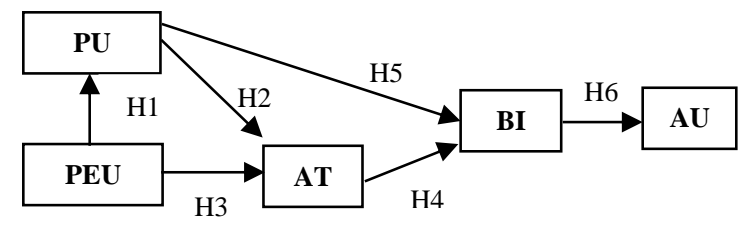

Gbr. 2 Konstruk Hipotesis

Dipandang dari cara pengumpulan data, pendekatan kuantitatif pada penelitian ini menggunakan survey dan wawancara terstruktur. Sedangkan metode pengumpulan datanya dengan menggunakan instrument kueisioner sebagai alat pengumpul data.

Setelah data dikumpulkan dilakukan proses analisis data. Proses analisis data menggunakan metode PLS. Dalam metode PLS untuk pengujian model dilakukan dua tahapan analisis, yaitu model pengukuran (outer model) dan model struktural (inner model) [8][9]. Gambaran alur analisis data dapat dilihat pada Gambar 3.

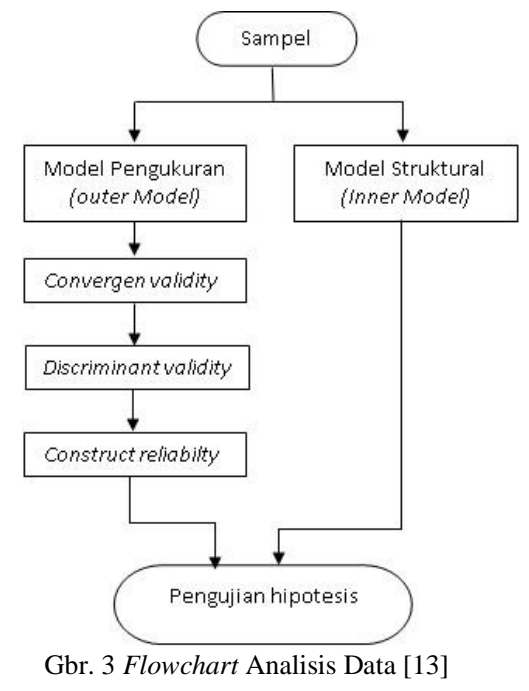

Proses analisis seperti Gambar 3. dimulai dari analisis outer model yang terdiri dari tiga kriteria dalam penilaiannya (convergent validity, discriminant validity dan contruct reliability), dan langkah selanjutnya dengan analisis inner model. Pengujian hipotesis dilakukan setelah outer model dan inner model.

\section{HASIL DAN PEMBAHASAN}

A. Hasil Penelitian

Data yang telah dikumpulkan kemudian diolah menggunakan metode PLS menggunakan Software Smart PLS 2.0 M3. Persamaan struktural Metode PLS dilakukan dengan 2 tahap yaitu melakukan model pengukuran (outer model) dan model struktural (inner model).

1. Model Pengukuran (Measurement/outer model)

Tahap yang dilakukan pada model pengukuran adalah menguji validitas dan reliabilitas dari 
indikator pembentuk variabel. kriteria yang digunakan untuk mengukur validitas menggunakan validitas konvergen dan validitas diskriminan dengan melihat nilai outer loading dan rerata ekstraksi varian (AVE). Sedangkan untuk mengukur reliabilitas diuji menggunakan nilai composite realibility dan Cronbach alpha.

a. Validitas Konvergen

Indikator-indikator dari suatu konstruk seharusnya berkorelasi tinggi terhadap dirinya sendiri yang tercermin dalam nilai loading faktor indikator. Kriteria nilai loading factor untuk penelitian bersifat confirmatory harus $>0,70$ dan penelitian yang bersifat exploratory antara 0,60 sampai 0,70 [9]. Indikator yang mempunyai nilai loading factor kurang dari 0,7 sebaiknya dihilangkan dari konstruk laten. Hasil dari loading factor yang pada Smart PLS dapat dilihat pada Gambar 4.

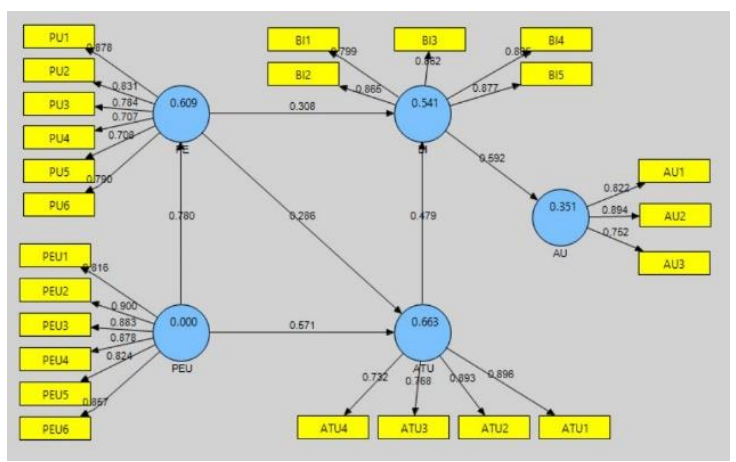

Gbr. 4 Proses Pengujian Loading factor Smart PLS

Gambar 4 menunjukkan tidak terdapat nilai loading factor kurang dari 0.7, sehingga indikatorindikator dalam penelitian dapat dikatakan memenuhi validitas konvergen dan sehingga memenuhi syarat valid dalam membentuk konstruk dimensinya. Hasil dari loading factor dapat dilihat pada Tabel 1 .

Tabel 1. Hasil Akhir Loading factor

\begin{tabular}{|l|l|l|l|}
\hline Konstruk & Indikator & Outer Loading & Validitas \\
\hline \multirow{3}{*}{$\begin{array}{l}\text { Sikap } \\
\text { Perilaku }\end{array}$} & ATU1 & 0.896 & Valid \\
\cline { 2 - 4 } & ATU2 & 0.8926 & Valid \\
\cline { 2 - 4 } & ATU3 & 0.7677 & Valid \\
\cline { 2 - 4 } & ATU4 & 0.7321 & Valid \\
\hline Penggunaan & AU1 & 0.8221 & Valid \\
\cline { 2 - 4 } & AU2 & 0.8941 & Valid \\
\cline { 2 - 4 } & AU3 & 0.7518 & Valid \\
\hline \multirow{5}{*}{\begin{tabular}{l} 
Niat Perilaku \\
\cline { 2 - 4 }
\end{tabular}} & BI1 & 0.7987 & Valid \\
\cline { 2 - 4 } & BI2 & 0.8645 & Valid \\
\cline { 2 - 4 } & BI3 & 0.8618 & Valid \\
\cline { 2 - 4 } & BI4 & 0.8848 & Valid \\
\cline { 2 - 4 } & BI5 & 0.8768 & \\
\hline
\end{tabular}

\begin{tabular}{|l|l|l|l|}
\hline Konstruk & Indikator & Outer Loading & Validitas \\
\hline Persepsi & PU1 & 0.8776 & Valid \\
\cline { 2 - 4 } Kegunaan & PU2 & 0.8305 & Valid \\
\cline { 2 - 4 } & PU3 & 0.7836 & Valid \\
\cline { 2 - 4 } & PU4 & 0.7074 & Valid \\
\cline { 2 - 4 } & PU5 & 0.7083 & Valid \\
\cline { 2 - 4 } & PU6 & 0.7902 & Valid \\
\hline \multirow{4}{*}{$\begin{array}{l}\text { Pemepsi } \\
\text { Penggunaan }\end{array}$} & PEU1 & 0.8161 & Valid \\
\cline { 2 - 4 } & PEU2 & 0.9002 & Valid \\
\cline { 2 - 4 } & PEU3 & 0.8828 & Valid \\
\cline { 2 - 4 } & PEU4 & 0.8778 & Valid \\
\cline { 2 - 4 } & PEU5 & 0.8235 & Valid \\
\cline { 2 - 4 } & PEU6 & 0.8574 & Valid \\
\hline
\end{tabular}

Selain nilai loading factor, nilai Average Variance Extracted (AVE) dan Communality juga dapat digunakan untuk mengukur validitas konvergen ${ }^{14}$. Communality adalah ukuran kualitas model pengukuran pada tiap blok variabel laten yang dihasilkan dalam proses iterasi algorithm PLS. Sedangkan AVE adalah rerata persentase skor varian yang diekstrasi dari seperangkat variabel laten yang diestimasi melalui loading standardize indikatornya dalam proses iterasi algorithm PLS. Nilai AVE dan communality dalam penelitian ini dapat dilihat pada Tabel 2.

Tabel 2 Nilai AVE dan Communality

\begin{tabular}{|l|r|l|}
\hline Konstruk & AVE & Communality \\
\hline Sikap terhadap Perilaku & 0.6812 & 0.6812 \\
\hline Penggunaan Nyata Sistem & 0.6801 & 0.6801 \\
\hline Niat Perilaku & 0.7359 & 0.7359 \\
\hline Persepsi Kegunaan & 0.6168 & 0.6168 \\
\hline Persepsi Kemudahan Penggunaan & 0.7399 & 0.7399 \\
\hline
\end{tabular}

Nilai AVE dan communality yang dihasilkan dari semua konstruk diatas 0.5 sehingga variabel konstruk dinilai valid sebagai syarat model yang baik.

b. Validitas Diskriminan

Selain validitas konvergen, validitas diskriminan juga digunakan untuk menguji validitas dari sebuah indikator variabel. varibael diskriminan bertujuan untuk membuktikan bahwa indikator pada tiap-tiap variabel laten memprediksi ukuran pada blok mereka lebih baik dari pada ukuran pada blok lainnya. Nilai validitas diskriminan dapat dilihat pada cross loading antara indikator dengan konstruknya yang dinyatakan pada Tabel 3 . 
Tabel 3. Hasil Cross Loading Indikator dengan Konstruk

\begin{tabular}{|l|l|l|l|r|r|}
\hline & ATU & AU & BI & PU & PEU \\
\hline ATU1 & 0.896 & 0.4268 & 0.7054 & 0.7398 & 0.8212 \\
\hline ATU2 & 0.8926 & 0.477 & 0.676 & 0.6889 & 0.7777 \\
\hline ATU3 & 0.7677 & 0.2499 & 0.4128 & 0.4403 & 0.4518 \\
\hline ATU4 & 0.7321 & 0.2584 & 0.4392 & 0.4516 & 0.4366 \\
\hline AU1 & 0.3466 & 0.8221 & 0.4569 & 0.3355 & 0.3671 \\
\hline AU2 & 0.4231 & 0.8941 & 0.5792 & 0.4375 & 0.5263 \\
\hline AU3 & 0.3337 & 0.7518 & 0.4084 & 0.3313 & 0.3849 \\
\hline BI1 & 0.6573 & 0.509 & 0.7987 & 0.6875 & 0.6532 \\
\hline BI2 & 0.5619 & 0.5493 & 0.8645 & 0.4871 & 0.623 \\
\hline BI3 & 0.6085 & 0.491 & 0.8618 & 0.5498 & 0.6666 \\
\hline BI4 & 0.5881 & 0.4574 & 0.8848 & 0.5487 & 0.6245 \\
\hline BI5 & 0.5943 & 0.526 & 0.8768 & 0.5328 & 0.6312 \\
\hline PU1 & 0.6554 & 0.423 & 0.6047 & 0.8776 & 0.6679 \\
\hline PU2 & 0.5641 & 0.3871 & 0.5254 & 0.8305 & 0.6628 \\
\hline PU3 & 0.4748 & 0.3395 & 0.4405 & 0.7836 & 0.5225 \\
\hline PU4 & 0.5605 & 0.3058 & 0.4953 & 0.7074 & 0.5108 \\
\hline PU5 & 0.561 & 0.3111 & 0.4852 & 0.7083 & 0.6259 \\
\hline PU6 & 0.6075 & 0.3474 & 0.5315 & 0.7902 & 0.6593 \\
\hline PEU1 & 0.5289 & 0.3696 & 0.5505 & 0.6261 & 0.8161 \\
\hline PEU2 & 0.6794 & 0.5062 & 0.6653 & 0.6397 & 0.9002 \\
\hline PEU3 & 0.7056 & 0.5228 & 0.6735 & 0.6827 & 0.8828 \\
\hline PEU4 & 0.7549 & 0.4584 & 0.6546 & 0.6673 & 0.8778 \\
\hline PEU5 & 0.6526 & 0.3992 & 0.6213 & 0.646 & 0.8235 \\
\hline PEU6 & 0.7459 & 0.4401 & 0.6789 & 0.7523 & 0.8574 \\
\hline
\end{tabular}

Hasil cross loading menunjukkan nilai blok indikator pada variabel mereka lebih bersar dari blok variabel lainnya.

c. Konstruk reliabilitas

Setelah dilakukan uji validitas, selanjutnya dilakukan uji reliabilitas. Uji reliabilitas penting dilakukan dalam penelitian ini yang diukur menggukan dua kriteria yaitu composite reliability dan cronbach alpha dari blok indikator konstruk. Sebuah konstruk dinyatakan reliabel jika nilai composite reliability diatas 0,70 dan nilai cronbachs alpha diatas sama dengan 0,50 .

\begin{tabular}{|l|l|l|}
\multicolumn{1}{|c|}{ Tabel 4 Nilai Uji Reliabilitas } \\
\hline \multicolumn{1}{|c|}{ Konstruk } & $\begin{array}{c}\text { Composite } \\
\text { Reliability }\end{array}$ & $\begin{array}{c}\text { Cronbachs } \\
\text { Alpha }\end{array}$ \\
\hline Sikap terhadap Perilaku & 0.8945 & 0.8497 \\
\hline Penggunaan Nyata Sistem & 0.8639 & 0.7645 \\
\hline Niat Perilaku & 0.933 & 0.91 \\
\hline Persepsi Kegunaan & 0.9056 & 0.8741 \\
\hline $\begin{array}{l}\text { Persepsi Kemudahan } \\
\text { Penggunaan }\end{array}$ & 0.9446 & 0.9295 \\
\hline
\end{tabular}

Hasil pengolahan data menunjukkan nilai composite realibility diatas 0.70 dan nilai cronbachs alpha diatas 0.5 . hal ini berarti semua konstruk memenuhi kondisi persyaratan tersebut sehingga model konstruk dalam penelitian dapat dikatakan handal digunakan.

2. Pengujian Struktural (Inner Model)

Setelah melalui tahap uji validitas dan reliabilitas pada outer model, selanjutnya dilakukan tahap Model struktural (inner model). tahap ini digunakan untuk menggambarkan hubungan antar variabel laten dalam kontruk model baik variabel dependen maupun variabel independen. Variabel independen tidak memiliki nilai $\mathrm{R}$ Square karena variabel tersebut tidak dipengaruhi oleh variabel lain dalam model. Variabel independent dalam penelitian ini adalah variabel Persepsi Kemudahan Pengguna, sedangkan variabel dependen dalam penelitian ini adalah variabel sikap terhadap perilaku, pengguna sistem nyata, niat perilaku dan persepsi kegunaan. Model struktural dievaluasi dengan menggunakan nilai R-square untuk konstruk dependen. Model yang kuat ditunjukkan dengan nilai >=0,67; model yang moderate ditunjukkan dengan nilai $>=0,33$ dan model yang lemah ditunjukkan dengan nilai $>=0,19$ [9]. Nilai R Square pada model penelitian dapat dilihat pada Tabel 5.

Tabel 5. Nilai R Square pada Variabel Konstruk Dependen.

\begin{tabular}{|l|l|}
\hline Konstruk & R Square \\
\hline Sikap terhadap Perilaku & 0.6626 \\
\hline Penggunaan Nyata Sistem & 0.3508 \\
\hline Niat Perilaku & 0.5409 \\
\hline Persepsi Kegunaan & 0.6090 \\
\hline Persepsi Kemudahan Penggunaan & - \\
\hline
\end{tabular}

Penjelasan dari Tabel 5. sebagai berikut.

a. Variabel sikap terhadap perilaku memiliki nilai R Square sebesar 0.6626 dapat diartikan bahwa validitas Sikap terhadap perilaku dapat dijelaskan oleh konstruk Persepsi kegunaan dan persepsi kemudahan pengguna sebanyak $66.26 \%$ sedangkan sisanya $34.74 \%$ dijelaskan oleh variabel lain yang tidak diteliti dalam penelitian ini.

b. Variabel penggunaan nyata sistem memiliki nilai $\mathrm{R}$ Square 0.3508 dapat diartikan bahwa validitas penggunaan nyata sistem dapat dijelaskan oleh konstruk niat perilaku sebanyak $35.08 \%$ sedangkan sisanya $65.92 \%$ dijelaskan oleh variabel lain yang tidak diteliti dalam penelitian ini.

c. Variabel niat perilaku memiliki nilai R Square 0.5409 dapat diartikan bahwa validitas Niat Perilaku dapat dijelaskan oleh konstruk persepsi kegunaan dan sikap terhadap perilaku sebanyak $54.09 \%$ sedangkan sisanya $46.91 \%$ dijelaskan oleh variabel lain yang tidak diteliti dalam penelitian ini.

d. Variabel persepsi kegunaan memiliki nilai $\mathrm{R}$ Square 0.6090 dapat diartikan bahwa validitas 
persepsi kegunaan dapat dijelaskan oleh konstruk Persepsi Kemudahan Penggunaan sebanyak $60.90 \%$ sedangkan sisanya $39.10 \%$ dijelaskan oleh variabel lain yagn tidak diteliti dalam penelitian ini.

3. Pengujian Hipotesis

Setelah dilakukan uji validitas dan reliabilitas indikator menggunakan outer model dan pengujian variabel model konstruk menggunakan inner model, selanjutnya adalah tahap pengujian hipotesis. Pengujian hipotesis yaitu dilakukan dengan cara melihat tingkat signifikasi antar variabel laten menggunakan hasil perhitungan nilai Path Cooeficien dan nilai T-Statistic. Untuk mengetahui nilai tingkat signifikasi maka dilakukan proses bootstraping pada software SmartPLS yang dinyatakan pada Gambar 5.

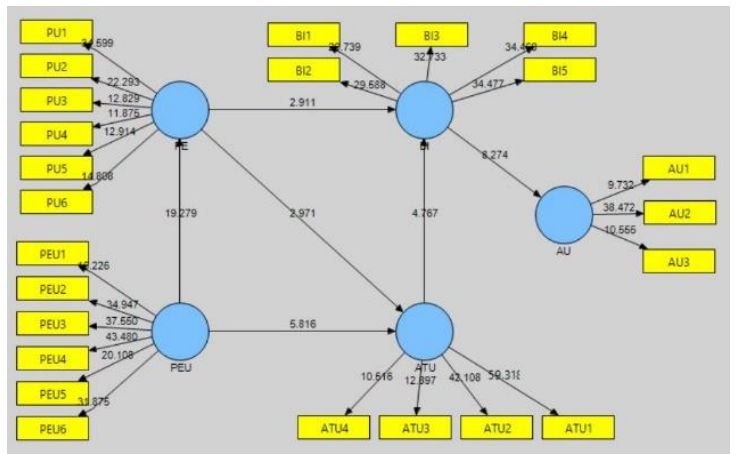

Gbr. 5 Hasil Pengujian Menggunakan Proses Bootstraping

Pengujian hipotesis dalam penelitian ini menggunakan tingkat signifikansi (significant level) $5 \%$ dan tingkat keyakinan (confidence level) $95 \%$ sehingga nilai t-statistik harus diatas 1,96 [15]. Hasil perhitungan nilai Path Coeficient dan T-Statistics yang diperoleh dari proses bootstaping pada model penelitian ini dapat dilihat pada Tabel 6.

Tabel 6. Nilai Path Coeficient dan T-Statistics

\begin{tabular}{|l|l|l|l|l|}
\hline H & Jalur & $\begin{array}{l}\text { Path } \\
\text { Cooeficient }\end{array}$ & $\begin{array}{c}\text { T-Statistics } \\
(\mid \text { O/STERR })\end{array}$ & Signifikansi \\
\hline H1 & PEU $\rightarrow$ PU & 0.7804 & 18.4059 & Signifikan \\
\hline H2 & PU $\rightarrow$ ATU & 0.286 & 3.2714 & Signifikan \\
\hline H3 & PEU $\rightarrow$ ATU & 0.5709 & 6.6601 & Signifikan \\
\hline H4 & ATU $\rightarrow$ BI & 0.4794 & 4.3135 & Signifikan \\
\hline H5 & PU $\rightarrow$ BI & 0.3081 & 2.5223 & Signifikan \\
\hline H6 & BI $\rightarrow$ AU & 0.5923 & 8.3141 & Signifikan \\
\hline
\end{tabular}

Hasil yang terdapat pada Tabel 6 menunjukkan hubungan antar konstruk signifikan karena Nilai TSatistiknya diatas 1.96 .

B. Pembahasan Penelitian

Pembahasan dari hasil penelirian sebagai berikut.

1. Hipotesis 1

Path Coeficient antara PEU dan PU bernilai 0.7804 atau searah dengan hipotesis yang disusun menunjukkan Persepsi Kemudahan Penggunaan berpengaruh signifikan terhadap Persepsi
Kegunaan. Nilai T-Statistics sebesar $18.4059>1.96$ menunjukkan bahwa hipotesis 1 diterima.

Korelasi positif antara konstruk Persepsi Kemudahan Penggunaan dan Persepsi Kegunaan menujukkan adanya pengaruh yang signifikan antar konstruk. Hal ini menggambarkan bahwa semakin mudah penggunaan E-Learning maka semakin baik juga kegunaan yang didapatkan oleh pengguna ELearning. Pengaruh signifikan yang dihasilkan berdasarkan indikator yang tertuang dalam bentuk pertanyaan kuisioner dan masukan responden yaitu, pengguna merasa E-Learning mudah dipelajari, memberikan informasi yang dibutuhkan, menggunakan Bahasa yang mudah dimengerti, fitur yang tersedia mudah digunakan dan langkahlangkah penggunaan E-Learning mudah diingat.

2. Hipotesis 2

Path Coeficient antara PU dan ATU bernilai 0.286 atau searah dengan hipotesis yang disusun menunjukkan Persepsi Kegunaan berpengaruh secara signifikan terhadap Sikap Terhadap Perilaku. Nilai T-Statistics sebesar $3.2714>1.96$ menunjukkan bahwa hipotesis 2 diterima.

Korelasi positif antara konstruk Persepsi kemudahan pengguna dan sikap terhadap perilaku menujukkan adanya pengaruh yang signifikan antar konstruk. Hal ini menggambarkan bahwa semakin tinggi penggunaan E-Learning maka semakin baik perilaku pengguna terhadap E-Learning. Pengaruh signifikan yang dihasilkan berdasarkan indikator yang tertuang dalam bentuk pertanyaan kuisioner dan masukan responden yaitu, E-Learning membantu dalam menemukan maeri perkuliahan, miningkatkan kinerja belajar, meningkatkan produktifitas, dan kemudahan dalam mengerjakan tugas. Namun beberapa responden juga merasakan bahwa E-Learning kadang terjadi gangguan terkhusus pada saat pengiriman pengumpulan tugas, kuis atau ujian.

3. Hipotesis 3

Path Coeficient antara PEU dan ATU bernilai 0.5709 atau searah dengan hipotesis yang disusun menunjukkan Persepsi Kemudahan Penggunaan berpengaruh secara signifikan terhadap Sikap Terhadap Perilaku. Nilai T-Statistics sebesar $6.6601>1.96$ menunjukkan bahwa hipotesis 3 diterima

Korelasi positif antara konstruk Persepsi Kemudahan Penggunaan dan Sikap Terhadap Perilaku menujukkan adanya pengaruh yang signifikan antar konstruk. Hal ini menggambarkan bahwa semakin semakin mudah pengguaan ELearning maka semakin baik perilaku pengguna terhadap E-Learning. Pengaruh signifikan yang dihasilkan berdasarkan indikator yang tertuang dalam bentuk pertanyaan kuisioner dan masukan responden yaitu, pengguna merasa E-Learning mudah dipelajari, memberikan informasi yang dibutuhkan, menggunakan Bahasa yang mudah dimengerti, fitur yang tersedia mudah digunakan 
dan langkah-langkah penggunaan E-Learning mudah diingat.

4. Hipotesis 4

Path Coeficient antara ATU dan BI bernilai 0.4791 atau searah dengan hipotesis yang disusun menunjukkan Sikap terhadap Perilaku berpengaruh secara signifikan terhadap Niat Perilaku. Nilai $T$ Statistics sebesar $4.3135>1.96$ menunjukkan bahwa hipotesis 1 diterima.

Korelasi positif antara konstruk Sikap Terhadap Perilaku dan Niat Perilaku menujukkan adanya pengaruh yang signifikan antar konstruk. Hal ini menggambarkan bahwa semakin baik Sikap terhadap E-Learning maka semakin tinggi Niat pengguna dalam menggunakan E-Learning. Pengaruh signifikan yang dihasilkan berdasarkan indikator yang tertuang dalam bentuk pertanyaan kuisioner dan masukan responden yaitu, pengguna merasa senang, nyaman dan suka menggunakan ELearning serta pengguna tidak merasa bosan dalam menggunakan E-Learning.

5. Hipotesis 5

Path Coeficient antara PU dan BI bernilai 0.3081 atau searah dengan hipotesis yang disusun menunjukkan Persepsi Kegunaan berpengaruh secara signifikan terhadap Niat Perilaku. Nilai $T$ Statistics sebesar $2.5223>1.96$ menunjukkan bahwa hipotesis 5 diterima.

Korelasi positif antara konstruk Persepsi Kegunaan dan Niat Perilaku menujukkan adanya pengaruh yang signifikan antar konstruk. Hal ini menggambarkan bahwa semakin tinggi kegunaan dari E-Learning maka semakin tinggi juga Niat pengguna menggunakan E-Learning. Pengaruh signifikan yang dihasilkan berdasarkan indikator yang tertuang dalam bentuk pertanyaan kuisioner dan masukan responden yaitu, E-Learning membantu dalam menemukan materi perkuliahan, miningkatkan kinerja belajar, meningkatkan produktifitas, dan kemudahan dalam mengerjakan tugas. Namun beberapa responden juga merasakan bahwa E-Learning kadang terjadi gangguan terkhusus pada saat pengiriman pengumpulan tugas, kuis atau ujian.

6. Hipotesis 6

Path Coeficient antara BI dan AU bernilai 0.5923 atau searah dengan hipotesis yang disusun menunjukkan Niat Perilaku berpengaruh secara signifikan terhadap Penggunaan Nyata Sistem. Nilai T-Statistics sebesar $8.3141>1.96$ menunjukkan bahwa hipotesis 6 diterima.

Korelasi positif antara konstruk Niat Perilaku dan Penggunaan Nyata Sistem menujukkan adanya pengaruh yang signifikan antar konstruk. Hal ini menggambarkan bahwa semakin tinggi Niat pengguna menggunakan E-Learning maka semakin tinggi juga intensitas pengguaan E-Learning. Pengaruh signifikan yang dihasilkan berdasarkan indikator yang tertuang dalam bentuk pertanyaan kuisioner dan masukan responden yaitu, Pengguna ingin menggunakan E-Learning pada saat perkuliahan maupun mengerjakan tugas, menggunakan E-Learning kapan saja, menggunakan E-Learning dalam mendukung proses belajar serta memotivasi teman untuk menggunakan E-Learning.

Tabel 7. Kesimpulan Pengujian Hipotesis

\begin{tabular}{|l|l|c|}
\hline Tabel 7. Kesimpulan Pengujian Hipotesis & \multicolumn{1}{|c|}{ Hasil } \\
H & \multicolumn{1}{|c|}{ Hipotesis } & Terbukti \\
\hline H1 & $\begin{array}{l}\text { Persepsi Kemudahan Penggunaan } \\
\text { (Perceived Ease of Use) berpengaruh } \\
\text { positif terhadap Persepsi Kegunaan } \\
\text { (Perceived Usefulness) pada } \\
\text { penggunaan E-Learning di STITEK } \\
\text { Bontang. }\end{array}$ & \\
\hline H2 & $\begin{array}{l}\text { Persepsi Kegunaan (Perceived } \\
\text { Usefulness berpengaruh positif } \\
\text { terhadap Sikap terhadap Perilaku } \\
\text { (Attitude Towards Using) penggunaan } \\
\text { E-Learning di STITEK Bontang. }\end{array}$ & \\
\hline H3 & $\begin{array}{l}\text { Persepsi Kemudahan Penggunaan } \\
\text { (Perceived Ease of Use) berpengaruh } \\
\text { terhadap Sikap terhadap Perilaku } \\
\text { (Attitude Towards Using) pada } \\
\text { penggunaan E-Learning di STITEK }\end{array}$ & \\
Bontang. Terbukti \\
\hline H4 & $\begin{array}{l}\text { Sikap terhadap Perilaku (Attitude } \\
\text { Towards Using) berpengaruh positif } \\
\text { terhadap NiatPerilaku (Behavioral } \\
\text { Intention) pada penggunaan E- } \\
\text { Learning di STITEK Bontang }\end{array}$ & \\
\hline H5 & $\begin{array}{l}\text { Persepsi Kegunaan (Perceived } \\
\text { Usefulness) berpengaruh positif } \\
\text { terhadap Niat Perilaku (Behavioral } \\
\text { Intention) penggunaan E-Learning di } \\
\text { STITEK Bontang. }\end{array}$ & Terbukti \\
\hline H6 & $\begin{array}{l}\text { Niat Perilaku (Behavioral Intention) } \\
\text { berpengaruh terhadap Penggunaan } \\
\text { Nyata Sistem (Actual Sistem Usage) } \\
\text { E-Learning di STITEK Bontang }\end{array}$ & Terbukti \\
\hline
\end{tabular}

\section{KESIMPULAN}

Berdasarkan hasil analisis data dan pembahasan dapat diambil kesimpulan bahwa Persepsi Kegunaan dan Persepsi Kemudahan Penggunaan berpengaruh secara signifikan terhadap Sikap Terhadap Perilaku, Persepsi Kemudahan Penggunaan berpengaruh secara signifikan terhadap Persepsi Kegunaan, Persepsi Kegunaan dan Sikap Terhadap Perilaku berpengaruh secara signifikan terhadap Niat Perilaku, serta Niat Perilaku berpengaruh secara signifikan terhadap Penggunaan Nyata Sistem. Secara umum, pengguna dapat menerima dan menggunakan E-Learning namun perlu adanya peningkatan kualitas sistem khususnya pada saat mengumpulkan tugas perkuliahan.

\section{Referensi}

[1] APJII, "Penetrasi \& Profil Perilaku Pengguna Internet Indonesia Tahun 2018," Apjii, p. 51, 2019.

[2] F. S. Rahayu, D. Budiyanto, and D. Palyama, "Analisis Penerimaan E-Learning Menggunakan Technology Acceptance Model (Tam) (Studi Kasus: Universitas Atma Jaya Yogyakarta)," J. Terap. Teknol. Inf., vol. 1, no. 2, pp. 87-98, 2017. 
[3] M. A. Setiawan, "Klasiber: A Floss Implementation to Build E-Learning System of Faculty of Industrial Technology, Islamic University of Indonesia; An Administrator Perspective," Semin. Nas. Apl. Teknol. Inf., vol. 2006, no. Snati, pp. 105-110, 2006.

[4] D. Napitupulu, "Kajian penerimaan e-learning dengan pendekatan TAM," Pros. Semin. Nas. Multidisiplin Ilmu Univ. Budi Luhur, Jakarta, no. April, pp. 41-48, 2017.

[5] F. D. Davis, "Perceived usefulness, perceived ease of use, and user acceptance of information technology," MIS Q. Manag. Inf. Syst., vol. 13, no. 3, pp. 319-339, 1989.

[6] D. Tang and L. Chen, "A review of the evolution of research on information Technology Acceptance Model," BMEI 2011 - Proc. 2011 Int. Conf. Bus. Manag. Electron. Inf., vol. 2, pp. 588-591, 2011

[7] V. Venkatesh and F. D. Davis, "Theoretical extension of the Technology Acceptance Model: Four longitudinal field studies," Manage. Sci., vol. 46, no. 2, pp. 186-204, 2000.

[8] J. R. T. Sitinjak and Sugiarto, LISREL. Graha Ilmu, 2006.

[9] I. Ghozali, Structural Equation Modeling Metode Alternatif dengan Partial Least Square (PLS). Semarang: Badan Penerbit Universitas Diponegoro, 2011.

[10] P. Tarka, "Likert scale and change in range of response categories vs. the factors extraction in EFA model," Acta Univ. Lodz. Folia Oeconomica, vol. 1, no. 311, 2015.

[11] R. Likert, "A Technique for the Measurement of Attitudes," Arch. Physcology, 1932.

[12] W. Budiaji, "Skala Pengukuran dan Jumlah Respon Skala Likert (The Measurement Scale and The Number of Responses in Likert Scale)," Ilmu Pertan. dan Perikan., vol. 2, no. 2, pp. 127-133, 2013.

[13] H. Latan and I. Ghozali, Partial least squares : konsep, teknik dan aplikasi SmartPLS 2.0 M3 untuk penelitian empiris. Semarang: Badan Penerbit Universitas Diponegoro, 2012.

[14] J. F. Hair JR, W. C. Black, B. J. Babin, and R. E. Anderson, Multivariate Data Analysis, 7th ed. Pearson, 2009.

[15] J. F. Hair, C. M. Ringle, and M. Sarstedt, "PLS-SEM: Indeed a silver bullet," J. Mark. Theory Pract., vol. 19, no. 2, pp. 139-152, 2011. 